\title{
Monitoring Left Atrial Pressure With a Useful Epidural Catheter
}

\author{
Arnaz Ahmet, MD, ${ }^{1}$ Altun Dilek, $\mathrm{MD}^{2}$ \\ ${ }^{1}$ Department of Cardiovascular Surgery, Acibadem Mehmet Ali Aydinlar University, School of Medicine, Istanbul, Turkey; ${ }^{2}$ \\ Department of Anesthesiology and Reanimation, Istanbul, Acibadem Bakirkoy Hospital, Turkey
}

\section{ABSTRACT}

Background: Left atrial pressure (LAP) monitoring provides a valuable option for management of hemodynamic status in pediatric congenital heart surgery during the postoperative period.

Methods: We used a Perifix Soft Tip 701 filter set catheter (B. Braun Melsungen AG 34209 Melsungen, Germany), which is commonly used for continuous epidural anesthesia. The catheter was placed into the left atrium to provide LAP monitoring. The study included 33 children, who needed LAP monitoring during and post-surgery between January 2016 and September 2017. Patients retrospectively were reviewed for ease of catheter placement, effectivity, accurate LAP, postoperative stability, and complications after removal of the catheter, including bleeding, air embolism, or thromboembolic events.

Results: Patients ranged in age from 2 days to 131.27 months (Mean 11.80 days \pm 25.76 days). Fifteen patients were newborn. Of the newborn patients, 39.4\% ( $\mathrm{N}=13)$ were female. Catheters successfully were implanted in all patients, and there were no procedural complications. Left atrial catheters were removed between 1 to 12 days, with an average of 3.55 days \pm 3.39 days before chest tube removal. During follow-up, patients did not suffer complications, such as thrombus formation, catheter-related infection, systemic embolism or stroke. Also, after the catheter was withdrawn, patients did not suffer from bleeding, haemodynamic deterioration, catheter retention, or require the need for intervention. During the stay in ICU, catheter nonfunction was the most frequent complication at 12.1 percent $(\mathrm{N}=4)$.

Conclusion: This is a simple, easy, and safe technique for wide use in congenital cardiac surgery patients.

\section{INTRODUCTION}

The monitoring of intracardiac pressures in patients undergoing corrective and palliative procedures for congenital and acquired cardiac disease has been well established. It has become almost routine to use some combination of right atrial (RA), left atrial (LA), and pulmonary artery (PA) catheters in such patients [Gold 1986; Salihoğlu 2013].

Received February 14, 2018; received in revised form May 5, 2018; accepted May 7, 2018.

Correspondence: Abmet Arnaz, Halit Ziya Usaklgil caddesi, Acibadem Bakirkoy Hastanesi, No 1, 34140, Bakırköy, İstanbul, Turkey; +905322753944, +902124144408; (email: abmetarnaz@yahoo.com).
The monitoring of left atrial pressure (LAP) is a valuable way to evaluate accurate and correct filling pressures of the left ventricle in the perioperative period until the hemodynamic status of the patient is stabilized. This technique is widely used in patients after cardiac surgery to manage volume and vasoactive therapy. With the development of better pharmacological agents and mechanical methods, it has become important to assess the correct cardiac functions particularly preload, pulmonary vascular resistance, systemic vascular resistance, and contractility. However, LA and the PA catheters largely are associated with some complications, namely bleeding, air embolism, and thromboembolism [Gold 1986].

We used an $18 \mathrm{G}$ Tuohy needle (Espocan + Docking System + Perifix Soft Tip, B. Braun Melsungen AG, D-34209 Melsungen, Germany), which is commonly used for continuous epidural anesthesia to decrease possible complications related to its small external diameter $(0.85 \mathrm{~mm})$.

The purpose of this study is to examine the use of this epidural catheter, its reliability, and monitor catheter complications.

\section{MATERIALS AND METHODS}

The study was approved by Acibadem Mehmet Ali Aydinlar University Ethics Committee and was conducted by the principles of the Declaration of Helsinki.

We included all patients, who received a left atrial catheter between Jan. 2016 and Sept. 2017.

Patients retrospectively were reviewed for ease of catheter placement, effectivity, accurate LAP, postoperative stability, and complications after removal of the catheter, including bleeding, air embolism, or thromboembolic events.

We used a Perifix epidural catheter, which is commonly used for epidural anesthesia, to follow perioperative and postoperative hemodynamic parameters, particularly in complex congenital cardiac surgeries.

In addition, all patients received conventional central venous monitoring lines preoperatively, including neonates and infants undergoing correction of complex congenital heart diseases.

\section{OPERATIVE TECHNIQUE}

The superior left pulmonary vein was used to place LA catheter in all cases.

The procedure was accomplished either still on cardiopulmonary bypass or after cardiopulmonary bypass.

An 18 G Touhy needle (Espocan + Docking System + Perifix Soft Tip, B. Braun Melsungen AG, D-34209 Melsungen, 

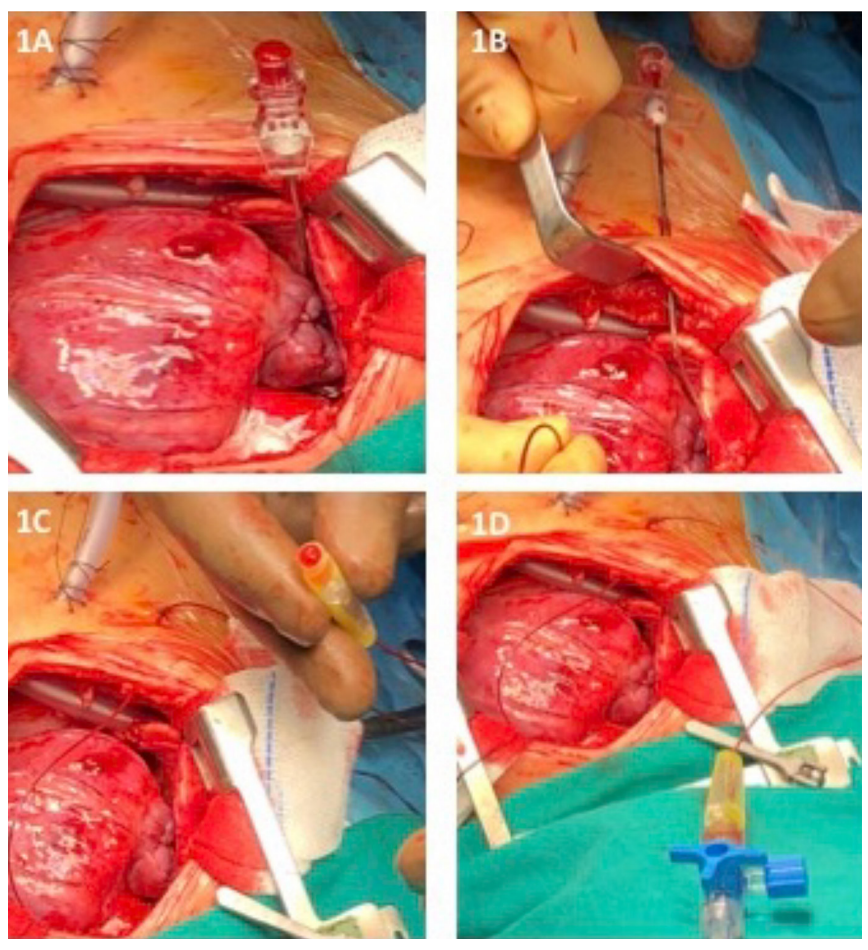

Stages of the catheter placing.

Germany) was inserted in the center of a 5-0 or 4-0 Prolene (Ethicon Inc., Somerville, NJ) pledgeted purse suture, which was placed to fix the catheter at the junction of the left atrial and right superior pulmonary vein.

The catheter was positioned to the LA through the needle; the needle was then withdrawn (Figure, A). The catheter was stabilized with the 5-0 pledgeted suture, which was placed previously to the right superior pulmonary vein and the right pericardium, keeping the minimum length of the distal side of the catheter inside the LA for appropriate monitoring. The other side of the catheter was pulled back to the outside of the mediastinum using the same needle, and the catheter was shortened as necessary and fixed to the skin (Figure, B).

The line was filled with the retrograde flow of left atrial blood to minimize the risk of gaseous microemboli (Figure, C). The catheter was routinely attached to a pressure transducer in the operating room to guide during the weaning off of cardiopulmonary bypass and to confirm the correct left atrial pressure (Figure, D). The position of the line itself was always manually established before the chest was closed.

A heparin flush (1000 units of heparin added to $500 \mathrm{~mL}$ of isotonic saline) was then maintained at a flow rate of $3 \mathrm{~mL} / \mathrm{h}$.

\section{RESULTS}

A total of 33 pediatric patients, who underwent surgery for congenital heart disease and needed LAP monitoring during the perioperative period, were enrolled in this study. The demographic and clinical characteristics of the patients are summarized in Table 1.
Table 1. Patient Demographics

\begin{tabular}{lcc}
\hline Age (Months) & Min-Max (Median) & 2 days-131.27 months (1.2 months) \\
\hline & Avg \pm SS & $11.80 \pm 25.76$ \\
Gender; N (\%) & Female & $13(39.4)$ \\
& Male & $20(60.6)$ \\
$\mathrm{BMI}\left(\mathrm{kg} / \mathrm{m}^{2}\right)$ & Min-Max (Median) & $0.17-1.33(0.26)$ \\
Avg $\pm \mathrm{SS}$ & $0.34 \pm 0.22$ &
\end{tabular}

When the diagnosis is examined; $48.5 \%(\mathrm{~N}=16) \mathrm{TGA}, 21.2 \%(\mathrm{~N}=7)$ CAVSD, 6.1\% ( $\mathrm{N}=2)$ TAPVD, 6,1\% $(\mathrm{N}=2) \mathrm{VSD}$, and $6.1 \%(\mathrm{~N}=1)$ ALCAPA, 3.0\% ( $N=1)$ Truncus arteriosus, 3.0\% $(\mathrm{N}=1)$ Supravalvular aorta and pulmonary artery stenosis, and 3.0\% $(\mathrm{N}=1)$ Subaortic stenosis with VSD was detected (Table 2).

The ages of the patients ranged from 2 days to 131.27 months, with a mean of 11.80 days \pm 25.76 days, and a total of 15 patients were newborn. Of the newborn patients, 39.4 percent $(\mathrm{N}=13)$ were female and 60.6 percent $(\mathrm{N}=20)$ were male. BMI measurements ranged from $0.17 \mathrm{~kg} / \mathrm{m}^{2}$ to $1.33 \mathrm{~kg} /$ $\mathrm{m}^{2}$ with an average of $0.34 \mathrm{~kg} / \mathrm{m}^{2} \pm 0.22 \mathrm{~kg} / \mathrm{m}^{2}$.

Arterial switch operations (ASO) were needed in 48.5 percent $(\mathrm{N}=16)$ of infants, CAVSD repair in 21.2 percent $(\mathrm{N}=$ $7)$, repair of TAPVD in 6.1 percent $(\mathrm{N}=2)$, VSD closure in 6.1 percent $(\mathrm{N}=2)$, complete repair for TOF in 6.1 percent $(\mathrm{N}=2)$, complete repair for ALCAPA in 3 percent $(\mathrm{N}=1)$, complete repair for truncus arteriosus in 3 percent $(\mathrm{N}=1), \mathrm{PA}$ and Ao reconstruction in 3 percent $(\mathrm{N}=1)$, atrial septectomy, aortic valvotomy and bilateral PA banding in 3 percent $(\mathrm{N}=$ 1) were performed in this study (Table 2).

Extracorporeal membrane oxygenation (ECMO) was needed in 4 patients (12.1 percent). The duration of ECMO ranged from 65 hours to 191 hours with a mean of 112.75 hours \pm 56.22 hours. CBP measurements ranged from 78 minutes to 412 minutes with a mean of 185.91 minutes \pm 79.97 minutes; ACC measurements ranged from 27 minutes to 224 minutes with a mean of 90.61 minutes \pm 39.12 minutes. Intubation times ranged from 0.17 days to 155 days with an average of 19.46 days \pm 30.23 days; ICU duration ranged from 2 days to 164 days with a mean of 24.03 days \pm 32.45 days (Table 3 ).

Catheters were successfully implanted in all patients. There were no procedural complications. LA catheters were removed between 1 to 12 days with an average of 3.55 days \pm 3.39 days before chest tube removal.

Bleeding was considered present when chest tube output in the hour after catheter removal was more than twice the average hourly output in the 6 hours before removal. Catheters were considered non-functional when there was dampened or no waveform tracing or when they could neither be infused through nor aspirate blood. Thrombus formation was considered when there was evidence on echocardiography. A catheter was considered infected only if cultures obtained from the catheter were positive for organisms.

There were no thrombus formations, infections, systemic embolisms, strokes during follow up, bleeding, hemodynamic 
Table 2. Diagnosis and type of operations

\begin{tabular}{lcc}
\hline & & $\mathrm{N}(\%)$ \\
\hline Diagnosis & TGA & $16(48.5)$ \\
CAVSD & $7(21.2)$ & \\
TAPVD & $2(6.1)$ & \\
VSD & $2(6.1)$ & \\
TOF & $2(6.1)$ \\
ALCAPA & $1(3.0)$ \\
Truncus arteriosus & $1(3.0)$ \\
Supravalvular AS + PA stenosis & $1(3.0)$ \\
Subvalvular AS + VSD & $1(3.0)$ \\
Operation & ASO & \\
CAVSD repair & $7(21.2)$ & \\
TAPVD repair & $2(6.1)$ \\
VSD closure & $2(6.1)$ \\
Complete repair for TOF & $2(6.1)$ \\
ALCAPA repair & $1(3.0)$ \\
Complete repair for truncus arteriosus & $1(3.0)$ \\
PA and Ao reconstruction & $1(3.0)$ \\
Atrial septectomy, aortic valvulotomy and & $1(3.0)$ \\
bilateral PA banding & \\
\end{tabular}

Transposition of great arteries (TGA); complete atrioventricular atrial septal defect (CAVSD); total anomalous pulmonary venous drainage (TAPVD); ventricular septal defect (VSD); tetralogy of Fallot (TOF); anomalous left coronary artery from the pulmonary artery (ALCAPA); aortic stenosis (AS); pulmonary artery (PA); arterial switch operation (ASO)

instability, catheter retention, or any need for intervention after removal of the LA catheter. LA catheter dysfunction was observed in 4 patients (12.1 percent). All non-functioning catheters were immediately removed.

In surviving patients, the time from LA catheter withdrawal to hospital discharge ranged from 2 days to 56 days with an average of 19 days \pm 15.25 days, whereas it ranged from 21 days to 158 days in non-surviving patients, with an average of 67 days \pm 54.54 days (Table 4$)$.

It was found statistically significant $(P=.004 ; P<.01)$ that the duration of the catheter withdrawal and hospital exit was higher in non-surviving patients than surviving patients. This finding suggests that mortality does not result from catheter withdrawal.

\section{STATISTICAL ANALYSIS}

NCSS (Number Cruncher Statistical System) 2007 (Kaysville, Utah, USA) program was used for statistical analysis. The Mann-Whitney U test was used to compare descriptive statistical methods (mean, standard deviation, median, frequency, ratio, minimum, and maximum) as well as quantitative data for two groups of non-normal distributions.
Table 3. Patient data

\begin{tabular}{|c|c|c|}
\hline & & $N(\%)$ \\
\hline ECMO & No & $29(87.9)$ \\
\hline Yes & $4(12.1)$ & \\
\hline ECMO duration (hours) $(\mathrm{N}=4)$ & Min-Max (Median) & 65-191 (97.5) \\
\hline Avg \pm SS & $112.75 \pm 56.22$ & \\
\hline CBP & Min-Max (Median) & $78-412(169)$ \\
\hline Avg \pm SS & $185.91 \pm 79.97$ & \\
\hline ACC & Min-Max (Median) & $27-224(81)$ \\
\hline Avg \pm SS & $90.61 \pm 39.12$ & \\
\hline Entubation duration (days) & Min-Max (Median) & $0.17-155(8)$ \\
\hline Avg \pm SS & $19.46 \pm 30.23$ & \\
\hline ICU duration (days) & Min-Max (Median) & $2-164(14)$ \\
\hline Avg \pm SS & $24.03 \pm 32.45$ & \\
\hline LA catheter duration (days) & Min-Max (Median) & $1-12(2)$ \\
\hline Avg \pm SS & $3.55 \pm 3.39$ & \\
\hline LA catheter complication & No & $33(100)$ \\
\hline Yes & $0(0)$ & \\
\hline LA catheter dysfunction & No & $29(87.9)$ \\
\hline Yes & $4(12.1)$ & \\
\hline Duration of hospitalization (days) & Min-Max (Median) & $7-164(22)$ \\
\hline Avg \pm SS & $31.27 \pm 33.17$ & \\
\hline Mortality & Surviving & $27(81.8)$ \\
\hline Non surviving & $6(18.2)$ & \\
\hline $\begin{array}{l}\text { Duration from LA catheter with- } \\
\text { drawal to hospital exit in patients } \\
\text { died (days) }(N=6)\end{array}$ & Min-Max (Median) & $21-158(48)$ \\
\hline Avg $\pm S S$ & $67.00 \pm 54.54$ & \\
\hline
\end{tabular}

Extracorporeal membrane oxygenator (ECMO); cardiopulmonary bypass (CPB); aortic cross clamp (ACC); intensive care unit (ICU)

\section{DISCUSSION}

The LAP monitoring is a valuable method for managing therapy during the weaning off of the cardiopulmonary bypass and postoperative period after surgical correction of complex congenital cardiac malformations, ischaemic heart disease with left ventricular dysfunction and repair procedures for the mitral valve [Gold 1986; Mondejar 1988; Haider 1993].

We found a very low rate of occurrence of severe complications and associated morbidities with use of this epidural catheter. During the ICU stays, catheter non-function was the most frequent complication (12.1 percent), but this resulted in no morbidity.

There are various methods to monitor LAP during this period. Inserting a catheter into the left atrium through the thoracic wall and throughout the right superior pulmonary vein can be used to monitor LAP. However, the primary 
Table 4. Comparison of duration between the LA catheter removal and hospital discharge in surviving and nonsurviving patients

\begin{tabular}{lccc}
\hline & Mortality & $\begin{array}{c}\text { Surviving } \\
(\mathrm{N}=27)\end{array}$ & $\begin{array}{c}\text { Nonsurviving } \\
(\mathrm{N}=6)\end{array}$ \\
\hline $\begin{array}{l}\text { The duration from removal of LA catheter to hospital discharge (days) } \\
\quad \begin{array}{l}\text { Median } \\
\text { Avg } \pm \text { SS }\end{array}\end{array}$ & Min-Max & $2-56(14)$ & $21-158(48)$ \\
\hline
\end{tabular}

*Mann Whitney $U$ Test

$\dagger P<0.01$

disadvantage of this method is bleeding after the catheter is withdrawn [Ceyran 2003; Flori 2000].

In our study, we did not face any bleeding and other morbidities, such as the need for intervention or hemodynamic instability related to catheter removal.

Another method is to place the distal orifice of a triple- or double-lumen catheter into the left atrium directly, but the distance between the distal and the central hole needs to be greater to avoid the central orifice located in the left atrium [Ceyran 2003; Fukutome 1993; Ueno 1993]. The most significant disadvantage of this method is catheter withdrawal: This not only needs to be restitched to fix the catheter, but this also comes with the risk of vasopressor extravasation from the third orifice, resulting in hemodynamic instability and tissue ischemia necrosis.

The other method is to use two different catheters, one triple-lumen catheter is placed into the superior vena cava, and the second single-lumen catheter is placed into the right atrium. The surgeon positions the tip of the single-lumen catheter from right to left in the atrium during the transatrial surgical procedure after repairing the primary defect. This method avoids bleeding complications; however, the risk of infection or obstruction of the superior vena cava is increased [Zahorec 1997; Rao 1993; Ding 2016]. Besides, it is difficult to puncture the jugular vein twice in pediatric patients, especially in newborns.

Before removal of direct transthoracic monitoring catheters, it's recommended that cross-matched blood and platelets be available and that patients be checked for coagulopathies [Ding 2016].

We recommend this catheter for LAP monitoring as it has demonstrated to be a simple, easy, and safe method for extensive use in pediatric cardiac surgery patients, such as those in Table 2 when LAP monitoring is required. We did not encounter bleeding complications. This is the major advantage over the transcutaneous insertion of a LAP monitoring line through the pulmonary vein or directly into the LA, which is associated with bleeding during withdrawal.

\section{REFERENCES}

Ceyran H, Akçali Y, Asgun F, Tezcaner T, Tasdemir K, Emirogullari ON, Ersepciler M. 2003. Benefit of using a triple-lumen catheter to monitor left atrial pressure. Acta Anaesthesiol Scand 47:430-2.

Ding J, Zhang Q, Li L, et al. 2016. A Novel Combined-Catheter to Monitor Left and Right Atrial Pressures. Pediatr Crit Care Med 17:210-5.

Flori HR, Johnson LD, Hanley FL, Fineman JR. 2000. Transthoracic intracardiac catheters in pediatric patients recovering from congenital heart defect surgery: Associated complications and outcomes 28:2997-3001.

Fukutome T, Kohjiro M, Sese A, Ueno Y. 1993. Trans-septal left atrial catheterisation. Anaesthesia 48:407-8.

Gold JP, Jonas RA, Lang P, Elixson EM, Mayer JE, Castaneda AR. 1986. Transthoracic intracardiac monitoring lines in pediatric surgical patients: A ten-year experience. Ann Thorac Surg 42:185-91.

Haider W, Zwolfer W, Hiesmayr M, et al. 1993. Improved cardiac performance and reduced pulmonary vascular constriction by epinephrine administration via a left atrial catheter in cardiac surgical patients. J Cardiothorac Vasc Anesth 7:684-7.

Mondejar EF, Torres JM, Moreno T, Vazquez G. 1988. The use of left atrial catheter after cardiac surgery. Intensive Care Med 14:441-2.

Rao PS, Sathyanarayana PV. 1993. Transseptal insertion of left atrial line: A simple and safe technique. Ann Thorac Surg 55:785-6.

Salihoğlu E, Gursoy M, Ozcobanoglu S, Ozkan S. 2013. Safety of surgical pulmonary artery catheters in pediatric patients. Turkish J Thorac Cardiovasc Surg 21:300-4.

Ueno Y, Sese A, Toshima Y, Fukutome T. 1993. Transvenous monitoring of left atrial and central venous pressure with a double-lumen catheter. Kyobu Geka 944-6.

Zahorec R, Holoman M. 1997. Transatrial access for left atrial pressure monitoring in cardiac surgery patients. Eur J Cardiothorac Surg $11: 379-80$. 